Martin Jenkins, COVENTRY UNIVERSITY, martin.jenkins@coventry.ac.uk Rena Bokosmaty, THE UNIVERSITY OF SYDNEY, rbok9807@uni.sydney.edu.au

Melanie Brown, RMIT VIETNAM, melanie.brown@rmit.edu.vn Chris Browne, AUSTRALIAN NATIONAL UNIVERSITY, chris.browne@anu.edu.au Qi Gao, BEIJING INSTITUTE OF TECHNOLOGY, gaoqi@bit.edu.cn Julie Hanson, UNIVERSITY OF THE SUNSHINE COAST, jhanson@usc.edu.au Ketevan Kupatadze, ELON UNIVERSITY, kkupatadze@elon.edu

\title{
Enhancing the Design and Analysis of Flipped Learning Strategies
}

\section{ABSTRACT}

There are numerous calls in the literature for research into the flipped learning approach to match the flood of popular media articles praising its impact on student learning and educational outcomes. This paper addresses those calls by proposing pedagogical strategies that promote active learning in 'flipped' approaches and improved practice of educational design in ICT supported learning environments. This paper makes two main contributions. It situates flipped learning strategies within a pedagogical framework, thus linking them to higher-level pedagogy. Additionally, it proposes an approach to both analysing and designing flipped learning strategies. This exploratory approach provides a guide for educators to map how their tactics fit amongst other instances of flipped learning. Examples of flipped learning approaches are provided to illustrate this mapping. The Flipped Learning Matrix, developed by this SoTL inquiry, is a tool for both critical reflection of existing approaches and course design, empowering the educator to design their own flipped version that is pedagogically sound and fit for purpose.

\section{KEYWORDS}

flipped learning, flipped classroom, Inquiry-based learning, educational design, pedagogical strategy

\section{INTRODUCTION: PROBLEMATIZING THE DEFINITION OF FLIPPED}

This paper proposes the use of an innovative 'Flipped Learning Matrix model' to examine the pedagogical strategies that promote improved educational design and active learning in flipped approaches. Although not a new pedagogical approach, flipped learning is currently often referenced in information and communications technology (ICT)-supported learning to describe an inversion of the traditional in-class and out-of-class components of the learning and teaching process.

The aims of this paper are: (i) to clearly identify the pedagogical strategies featured in flipped learning approach and, (ii) to create a design framework that provides operational guidance on how flipped learning approaches work.

Flipped learning approaches to pedagogy are not new; however, the terms flipped classroom and flipped learning are. Their relatively recent emergence and popularity reflect the accessibility of, and associated expectation for, how technology can be integrated into the learning process, be that to provide access to information, to offer feedback, or to create opportunities for faculty-student 
interactions. The popularity of the flipped classroom or flipped learning is not matched by widespread clarity over what the approach entails and how it is implemented. As a result, there are numerous calls in the literature for further research and investigation into this approach and the impact it may have on learning (Abeysekera \& Dawson, 2015; O’Flaherty \& Phillips, 2015).

A commonly accepted interpretation of flipped classroom is exemplified in the definition provided by Educause, where it is stated that "the flipped classroom is a pedagogical model in which the typical lecture and homework elements of a course are reversed” (2012, p. 1). A simple definition has come to be associated with the model in which lectures are video and/or audio taped beforehand by the teacher in order to spend classroom time problem solving. Alternatively, flipped learning, as defined by the Flipped Learning Network (2015), describes:

A pedagogical approach in which direct instruction moves from the group learning space to the individual learning space, and the resulting group space is transformed into a dynamic, interactive learning environment where the educator guides students as they apply concepts and engage creatively in the subject matter.

The Flipped Learning Network's description provides a broader perspective on what is encompassed in a flipped learning design. It suggests that, in order for the model to offer enhanced opportunities for deeper, more active, and engaged learning, the process of flipping has to be well thought out, intentional and holistic. This definition of flipped learning expands on the basic idea of the flipped classroom's inversion of the teaching and learning dynamics, emphasising that the opportunities for interaction in the 'group learning space' are utilised and not taken up with 'direct instruction.'

A review of the literature reveals that there is no one original source of the flipped learning concept, and the search for its origins or an authoritative definition is complicated by the various interpretations, implementations, and terms in use. For example, Mazur's 'peer instruction' (1997) has similar characteristics to a flipped approach; Lage, Platt, and Treglia (2000) discuss 'inverted classrooms'; and Bergmann \& Sams' (2012) use of the 'flipped' or 'inverted' classroom is widely known. There have also been variations in interpretation across disciplines. Within the humanities, it is asked whether a flipped approach is actually new, given that discussion-based classes have long substituted traditional lectures (Berens, 2014). Within science, technology, engineering and mathematics (STEM) subjects there have been numerous investigations into the use of video resources before class, enabling face-to-face time to take on a more active mode (Redekopp \& Ragusa, 2013; Zappe, Leicht, Messner, Litzinger \& Lee, 2009). Across the board, however, there is a noticeable lack of scholarly investigation into the flipped approach (Abeysekera \& Dawson, 2015).

The flipped classroom, then, is generally conceived as describing an inversion of the process of teaching and learning, i.e., traditional lecture is recorded for students to hear outside the classroom while they focus on problem-solving activities inside it. We believe that such an understanding is limiting. A more holistic view of flipped learning informed by appropriate high-level pedagogy can be transformative rather than substitutive. As such, while the term flipped is relatively new, we consider flipped learning design to be a common-sense addition to such pedagogical strategies that support active and engaged learning.

\section{SITUATING FLIPPED LEARNING WITHIN A PEDAGOGICAL FRAMEWORK}

In a review of research into flipped learning, O'Flaherty and Phillips (2015, p.94) state that 'the flipped classroom is seen as a strategy that can genuinely improve the student learning experience 
through increased interactivity.' Yet they also conclude that (i) educators involved in curriculum renewal may not fully understand the pedagogy of how to effectively translate the flipped class into practice, and (ii) there appears to be misunderstanding of the key elements necessary for successful flipping and the link between pre- and face-to-face sessions. This study seeks to provide a model that helps clarify practice and inform design, recognising there is no one approach to flipped learning.

If we consider flipped learning as a strategy to assist in achieving learning outcomes, we can situate our analysis of flipped learning design using Goodyear's (2005) pedagogical framework. Goodyear proposes four layers in the pedagogical framework: pedagogical philosophy, high-level pedagogy, pedagogical strategies and pedagogical tactics. According to Goodyear (2005), pedagogical philosophy refers to the how educators think people learn and what knowledge consists of. High-level pedagogy encompasses broad approaches such as problem-based learning or collaborative knowledge building. Pedagogical strategy is the means used to achieve learning such as online debates. Tactics are defined as the detail methods that educators use to set tasks, encourage participation and offer guidance and feedback. This mapping to our investigation of flipped learning is presented in Table 1.

Table 1. A flipped learning design mapped to Goodyear's (2005) framework

\begin{tabular}{l|l}
\hline GOODYEAR'S FRAMEWORK & FLIPPED LEARNING APPROACH \\
\hline Pedagogical philosophy & An engaged community of learners \\
\hline High-level pedagogy & $\begin{array}{l}\text { Active, experiential learning, community of inquiry } \\
\text { framework (Garrison, Anderson, \& Archer, 2010) }\end{array}$ \\
\hline Pedagogical strategy & Flipped learning design \\
\hline Pedagogical tactics & Activities inside and outside the classroom \\
\hline
\end{tabular}

In this section, we situate flipped learning design as a strategy to achieve these higher-level pedagogical aims.

\section{Philosophy and high-level pedagogy}

The philosophy and high-level pedagogy layers do not provide 'prescriptions for action' (Goodyear, 2005, p. 87) but rather provide overarching pedagogical goals. We propose that there should be two pedagogical objectives of a flipped learning design: i) to increase active interactions between staff and the learner within the face-to-face time, and ii) to develop a community of learners who can support each other.

Kolb's model of Experiential Learning (1984) is a suitable high-level pedagogy to describe the active learning component of a flipped learning design. This was illustrated by Gerstein (2012) who applied Kolb's model to flipped learning. The objective to develop a community of learners is explored in Dewey (1916) and Lipman's (2003) arguments on reflective and democratic educational philosophy. The Dewey and Lipman theoretical foundations were later expanded on by the Community of Inquiry (CoI) Model (Garrison, Anderson, \& Archer, 2010) to promote social learning processes in online contexts. 
Such high-level pedagogies will encourage increased student engagement, combined with understanding and applying higher-order knowledge and skills, and developing students' self-learning skills; attributes that have been identified by Mason, Shuman, and Cook (2013) as applicable to the flipped approach.

\section{Pedagogical strategy}

As the high-level pedagogies do not provide instructions on how to design or compare versions of a flipped learning design, we propose a matrix to assist in understanding a flipped learning design.

The focus of this paper is on providing support for educational strategy and actions. Hence, this study adopts an exploratory method to analyse strategies and actions for flipped learning. Graham, Henri, \& Gibbons (2014) identify 'explore' models as a means to define and categorise groupings and relationships, providing a basis for explaining and understanding the processes that are involved in blended learning approaches.

Table 2. Explore, explain and design frameworks for blended learning research (Graham et al. 2014, p. 15)

\begin{tabular}{c|l}
\hline EXPLORE & $\begin{array}{l}\text { Answers "what exists" } \\
\text { Defines } \\
\text { Categorises }\end{array}$ \\
\hline EXPLAIN & $\begin{array}{l}\text { Answers "why does this happen" } \\
\text { Looks for causation and correlation }\end{array}$ \\
\hline DESIGN & $\begin{array}{l}\text { Answers "How do I achieve this outcome" } \\
\text { Describes 'operational principles' that make an intervention or design work }\end{array}$ \\
\hline
\end{tabular}

Using a design framework, we can provide teachers with a tool to consider the different approaches to flipped learning.

\section{ANALYSING THE FLIP}

Matrix models based on two continua have been used to describe variation in pedagogical tactics. Such models provide a basis for explaining and understanding the motivations and processes that are involved. Healey (2005) used content-process and student-as-participants/students-as-audience continua to develop a matrix model for the research-teaching nexus. In describing different approaches to Inquiry-Based Learning (IBL), Levy (2015, p. 295) has used a matrix model based on two broad dimensions: content/process and generic/personal (Levy, Little, McKinney, Nibbs, \& Wood, 2009; Levy, 2015).

Figure 1 provides an example of an exploratory model as described by Graham et al. (2014). It provides a means to describe broadly different approaches to flipped learning. In this way, it provides a mechanism that can help practitioners situate their existing practice by providing a more inclusive interpretation of what flipped learning might look like.

Underpinned by IBL principles, our matrix model emphasises a strongly student-centred pedagogical tactic and aligns well with the philosophical lens that needs to be applied in flipped learning. We argue that flipped learning connotes a shift to the pedagogical philosophy that delivers inquirybased, egalitarian or democratic education. 
Our proposed matrix draws upon the high-level pedagogy identified earlier to define two continua: a) experiential learning - focus on skills development and self-learning (learning process/learning content) and b) autonomy and decision-making- the degree to which it encourages student autonomy (teacher-led/learner-led). These two continua for flipped learning, learning process and student autonomy, can be used to create a matrix model that defines and categorises different tactics for flipped learning, shown in Figure 1. We have described these categories as: Identifying, Producing, Authoring and Pursuing.

Figure 1. Flipped learning matrix: An adaptation of Levy et al. inquiry-based matrix to define and categorise flipped approaches across two continua (Click image for interactive version)

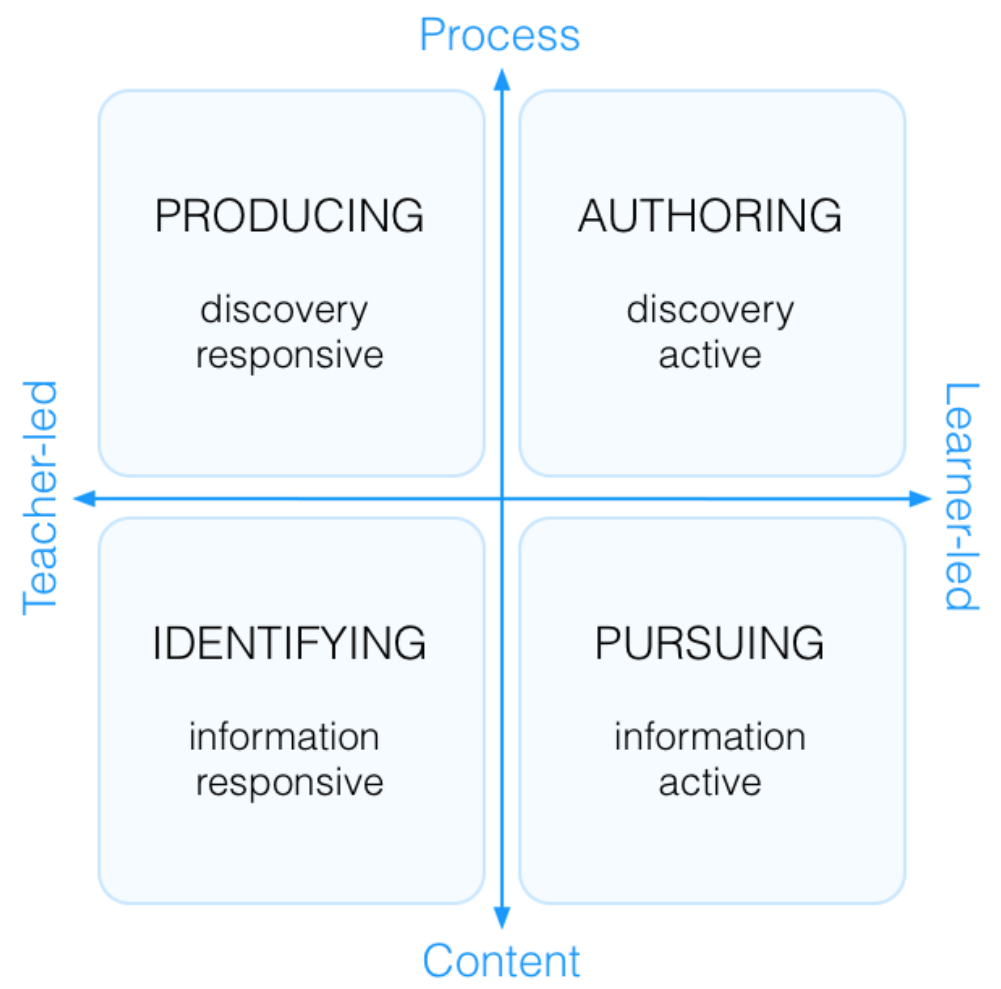

The categories in this matrix offer guidance for the mapping of Goodyear's fourth layer, pedagogical tactics, to strategies that teachers can use to achieve the higher level goals.

\section{Pedagogical tactics}

Using the two dimensions to produce the matrix model, it is possible to identify four broad categories of flipped learning approach within which tactics can be situated; these being:

- Identifying (Information Responsive): predominantly demonstrating faculty-led, contentfocused approaches, such as enhancement of a traditional lecture mode;

- Pursuing (Information Active): predominantly demonstrating student-led, content-focused approaches, such as self-directed student collaborations;

- Producing (Discovery Responsive): predominantly demonstrating faculty-led, processfocused approaches, such as developing critical thinking skills using IBL approaches; 
- Authoring (Discovery Active): predominantly demonstrating student-led, process-focused approaches, such as developing student-created content.

This Flipped Learning Matrix model provides a schema for analysing flipped learning approaches that will help to illuminate the range of potential characteristics of this approach.

\section{MAPPING PRACTICE: LOCATING INITIATIVES IN THE MATRIX}

The following sections provide a more detailed categorisation of each quadrant to demonstrate how tactics for flipped learning can be plotted against the matrix to aid in analysing the pedagogical approach. Each section is also illustrated with a case study which has been chosen as a representative example of the different quadrants in their tactics for flipping, shown in Figure 2. The quadrants should not be seen as discrete. It is recognised that in practice there will be overlap among the quadrants; in this matrix they provide a schema that allows exploration and consideration of different flipped tactics.

Teacher presence relates to where a teacher may be providing facilitation and/or direction (Garrison et al., 2010) and is used in these case studies as being distinct from actions that would indicate learner presence. Learner presence is suggested as an addition to the CoI framework (Shea \& Bidjerano, 2010; Shea, Hayes, Smith, Vickers, Bidjerano, Pickett, \& Shoubang, 2012) and recognises the active participation of learners through their meta-cognitive processes, motivation and behaviour.

Figure 2. Example initiatives mapped to the flipped learning matrix (Click image for interactive version)

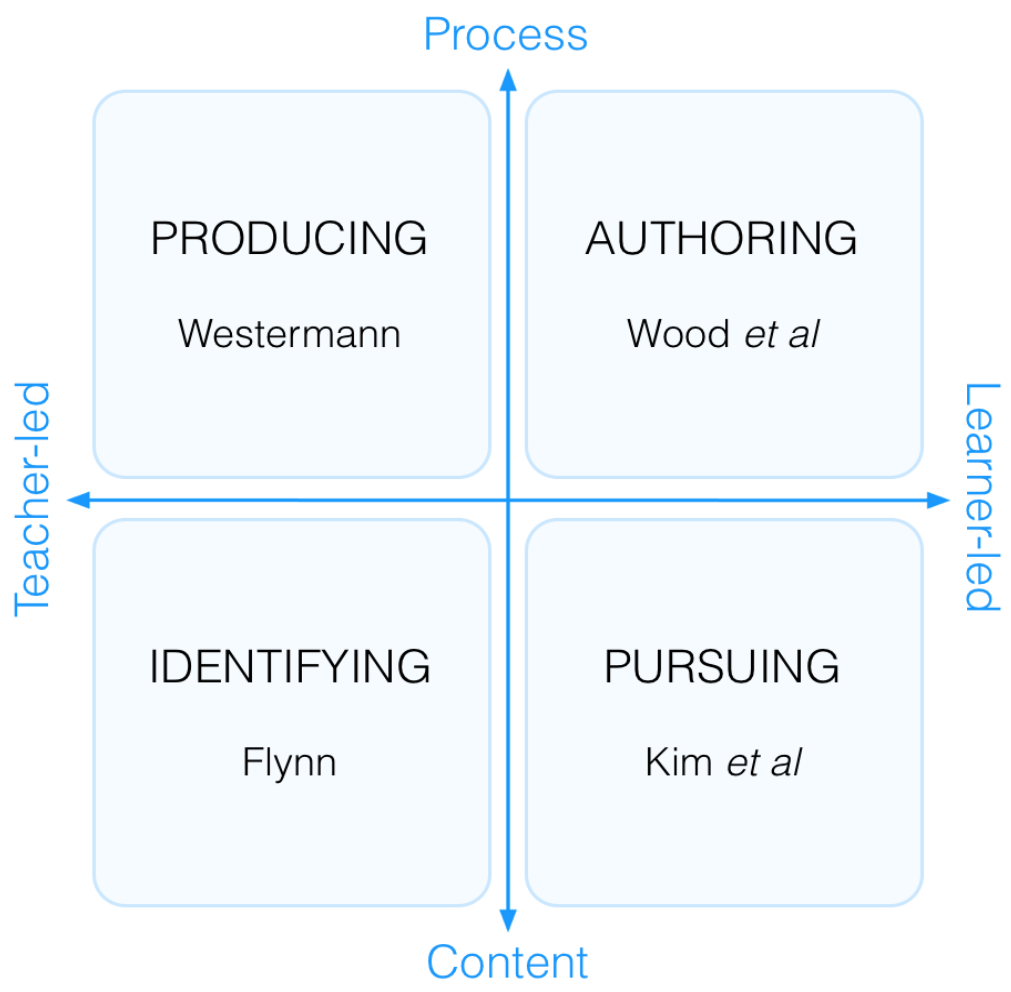

\section{Identifying: Information responsive}

A flipped learning design representative of this quadrant would demonstrate high levels of teacher presence. While allowing for active or inquiry-based approaches there would be limited opportunities for student decision-making in the learning process. The design would be focused more on content acquisition than skills or capability development. Social interaction will be dominated by 
teacher-learner interaction. Designs would be typified by a highly structured learning environment. Typical tactics in this quadrant would include:

- Outside class: video or audio lectures; readings (online or paper-based); use of quizzes to monitor understanding; discussion forums with the instructor.

- Inside class: problem sheets and activities; instructor-led class discussions; question and answer; personal-response systems.

Flynn (2015) describes a flipped learning approach implemented in a series of chemistry courses. The activities in this example map predominantly to the Identifying quadrant of the matrix, demonstrating a guided structure and predictable student responsibilities (Flynn, 2015, p. 207). Online activities, in the form of short videos and pre-class tests, were used to assess students' knowledge of the introductory concepts, thus addressing lower levels of Structure of Observed Learning Outcomes (SOLO) (Biggs \& Collis, 1982) and Bloom's taxonomy (Bloom, Engelhart, Furst, Hill, \& Krathwohl, 1956). The results obtained from the pre-class tests informed the class activities (Flynn, 2012) allowing the instructors to clarify students' misconceptions of particular concepts. The in-class learning activities were designed to address the higher levels of SOLO and Bloom so students engaged in deeper learning. This included problem-solving tasks, a classroom response system, think-pair-share, and predictobserve-explain activities. This structure increased student engagement and interaction with the course content as they constructed their own knowledge with each other and through the discussion with the instructors. Additional learning activities were available outside of the class time, such as tutorials, discussion forums, and consultations to address further questions from students. The weekly structure of the courses ended with an online assignment to assess the learning outcomes achieved by the students for each module.

The design of these courses reflects a classic interpretation of flipped learning, taking a "learning outcome-based approach to focus on what the student demonstrably knows and can do after instruction, rather than what the instructor teaches" (Biggs \& Tang, 2007 cited in Flynn, 2015, p. 200). Evaluation of the implementation suggests that the flipped classroom model improved students' grades, and reduced failure rate and withdrawal. Student surveys indicated a high satisfaction with the structure of the learning activities in these courses.

\section{Pursuing: Information active}

A flipped learning design representative of this quadrant would demonstrate greater learner presence. There would be an emphasis on content acquisition rather than skills or capability development, yet the design would encourage a greater mix of social interaction, including learnerlearner as well as teacher-learner. Learner presence would also be evidenced through greater selfregulation, goal-setting and monitoring. Teacher presence would be more facilitative in a structured environment working with an existing body of knowledge; a focus more on problem-solving than inquiry. These designs would encourage more creativity in student learning. Typical tactics in this quadrant would include:

- Outside class: students find and curate resources for use in-class.

- In class: role-play activities; in-class discussion; inquiry-based activities; peer feedback.

Kim, Kim, Khera, and Getman's (2014) study of flipped learning investigated three different approaches to flipped learning, in three different disciplines: Engineering, Humanities and Sociology. The Humanities example in the Kim et al. (2014) paper is a case that illustrates elements of the Pursuing quadrant. The flipped approach was used to provide a framework for student-focused activity while the 
teacher was absent. Students were tasked with preparing for student-led in-class discussions which were recorded for the teacher to provide online feedback. Out of class activities involved student preparation for the assignments set. This case provides an example of how different elements of the quadrants can be seen in individual cases. We have chosen to primarily locate this example in the pursuing quadrant given the student-directed nature of the activity.

The major design principles of this flipped instructional approach were: self- and co-regulated, recorded small-group discussions without the presence of the instructor; flipped role of the instructor and students; and the use of video-chat technology, video camera, and Dropbox, to enable learning. This particular instructor experimented with radical student-directed learning with the instructor absent. Students were given prompts and role-playing scenarios that guided the small-group discussions, which students then had to edit and record for the instructor. While the activity was designed with the purpose of promoting students' self-directed dialogue without teacher presence, the recording was to work "as a tool that helped the instructor monitor student discussions remotely” (Kim et al., 2014). The recordings were later uploaded on YouTube for two major purposes: $a)$ to be shared with the instructor; and b) to be edited artefacts. Kim et al. (2014, p. 39) suggest this approach was seen by students' as providing an 'authentic self-regulated conversation' impacted upon by the recording component which appeared to be redundant.

\section{Producing: Discovery responsive}

A flipped learning design representative of this quadrant would demonstrate a focus on learning processes within a structured learning environment that has a high level of teacher presence. This might be illustrated through teacher-directed inquiry based approaches which would be expected to evidence high levels of student goal-setting and reflective learning. Social presence would be evidenced through teacher-facilitated group work. Typical tactics in this quadrant would include:

- Outside class: students prepare information/presentation based on teacher defined parameters; peer evaluation.

- In class: case-based activities; seminar; presentation; teacher feedback; revision of student work.

Westermann's (2014) study uses a flipped learning approach in an upper level history class. The activities in this example map predominantly to the Producing quadrant of the matrix. The instructional model combined in-class and online learning activities to: a) promote a student-centred learning environment, b) augment the instruction with technology, and c) emphasise peer-to-peer and studentinstructor collaboration. The instructor used online activities to target lower levels of cognitive work, reserving in-class activities for higher levels of cognitive work (Westermann, 2014).

The flipped design included instructor identified primary resources being made available to students who were then expected to evaluate and question the resources, which has a process focus. The primary resources were made available online, using prompt questions to ensure students obtained an understanding of these readings and required introductory material for the face-to-face session. The students were required to respond to the online questions via an online forum; students were encouraged to peer evaluate each other's posts to initiate discussion. Further, students composed a micro-essay of approximately 200 words to answer additional questions posted by the instructor. The interactive element of the flipped design was delivered both online and face-to-face. Online, prior to the class session, the instructor provided feedback to clarify student responses. The in-class interaction time was then dedicated to students sharing their micro-essays in small groups to encourage them to 
collaborate with each other before sharing their insights with the rest of the class. Throughout this process, the instructor facilitated the discussion whilst simultaneously offering clarification when required. Following this, the students had the opportunity to revise their micro essays prior to submitting them for grading the next class. The whole design strongly emphasised the learning process.

Students' feedback towards the changes implemented in the course were overwhelmingly positive. They particularly highlighted that the nature of this student-centre approach provided them with the opportunity to understand the material of the course deeper whilst developing their critical thinking skills.

\section{Authoring: Discovery active}

A flipped learning design representative of this quadrant would demonstrate high degrees of learner autonomy and a focus on the learning process. The teacher's role is supportive and facilitating, with students in the stronger role of goal setting and monitoring. Designs in this quadrant would encourage both creativity and reflective learning. Social presence would emphasise learner-learner communication and peer-support. Typical tactics in this quadrant would include:

- Outside class: students involved in creating resources; project work.

- In class: teachers facilitate and support work on projects, no structured content; student-led discussion and presentation; peer feedback.

Wood, Bell, Hill, Huntington, and Scorpo (2014) used a flipped learning approach in a digital history course. The activities in this example map predominantly to the Authoring quadrant of the matrix. The instructors adopted this pedagogical approach as it focussed on the role of the students as collaborators in the production of knowledge; demonstrating high levels of student autonomy and a focus on the learning process.

The focus of the design is on the students being required to develop e-learning resources, using a web-based learning materials development tool, that were then shared with their peers as resources. Through this process students were engaged in developing a research-based online learning tool that required them to develop higher order thinking skills and encouraged them to work individually and collaboratively in creating their lesson. As an example of blended delivery, the content element of the design was a guide, with criteria for what their resource should include provided by the instructors. For the interactive element of the flipped design, delivered both online and face-to-face, the emphasis was on providing support and guidance to the students (Wood et al., 2014). The flexibility of developing this resource provided students with a sense of ownership, allowing them the opportunity to effectively use technology to present information in a digital format whilst developing their knowledge of the subject as well as working collaboratively in this learning environment. Wood et al., (2014) observed that the quality of the students' work was improved as a result of the changes made to the course, evidenced through higher grades.

\section{DISCUSSION}

One criticism of explore models of 'blended' learning systems has been that they tend to focus on physical rather than pedagogical structuring (Graham et al., 2014). Additionally, they fail to set tight parameters on how the teaching model can be enacted (Staker \& Horn, 2012). In this study, we emphasise that a pedagogical focus is an integral part of any flipped approach. Rather than setting fixed parameters on how flipping works, we argue that having a framework with which to analyse flipped 
tactics will allow flexible interpretations of flipping in different contexts as well as a basis for further research into the actual impact this approach has on learning.

Analysis of the four broad descriptions of flipped tactics and the examples of actual flipped learning design indicate how attention to the two continua of learning process and student autonomy can inform flipped designs.

Flipped learning pedagogy stems from the premise of inquiry-based and egalitarian philosophy: with the growing access to vast information through the internet, the traditional model of teacher as the sole steward of knowledge has become obsolete. In the new reality, teachers have acquired a new role: that of mediator, helping students transform the information that can be easily accessed into knowledge. This requires that students be active and engaged participants in their learning process and teachers be facilitators in the process. In the flipped learning environment that we advocate, the traditional role of students as passive recipients of knowledge is substituted by their active search for information followed by the process of analysis, negotiation of ideas, and subsequent transformation of information into knowledge. As it fosters student participation, flipped learning potentially increases their responsibility, creating a community of learners who, through collaborative work, are responsible for each other's learning and form a community of inquiry.

We have used the Flipped Learning Matrix model for locating different flipped designs of teaching based on clear educational philosophies and high-level pedagogies. Instances of instruction can be mapped onto quadrants, demonstrating that flipped learning can have multiple facets and interpretations, and we argue that the educator should be comfortable with this broad conceptualisation. To further this idea in relation to the model, we argue that not only does flipped learning exist in different forms as exemplified by the four quadrants, but more importantly, a flipped learning implementation could demonstrate elements from across the quadrants.

The complete design of a course has many facets, such as the face-to-face interactions, before and after class study and, obviously, assessment. This framework can be used to explore how these facets could be balanced within a course, and provides the educator with a useful method of navigating flipped course design. We propose that, in the re-design of a course or task to a flipped mode, the educator consider not only moving to the appropriate quadrant for the task, but also consider how the other three quadrants can be leveraged to improve the implementation of the task.

Take the typical example of flipping a traditional lecture within the context of a course. A simple instance of flipping would be to situate the approach in the Identifying quadrant, replacing the lecture with a video or audio recording. The matrix can be used to help inform discussion and decision-making for moving to a more active, problem-based mode in the Authoring quadrant. In this instance of flipping, the educator could use the matrix to help inform a developmental approach to the use of flipping, drawing upon elements of each quadrant. For example, prior to attending the Authoring face-to-face class, relevant information could be used to orientate the student to the content using short videos (Identifying). Students could be given a pre-task before attending the face-to-face class that encourages them to research a focus question set by the educator (Authoring), which could become the basis for the face-to-face interaction. As an out-of-class activity, students might be required to refine their focus question and reflect on the content (Pursuing) as part of a learning portfolio.

A different educator might implement flipping by moving away from a teacher-centred approach (Identifying) to a student-centred research project (Authoring). In doing so, the educator could provide relevant readings and resources (Identifying) and require milestones of smaller tasks to orientate the learner's direction (Pursuing). The educator could hold workshops (Producing) to meet the observed needs of the projects at appropriate times, such as writing workshops or peer review sessions. 
Beyond the course level, the matrix could also be employed in mapping a program level approach to introducing flipped learning. For example, a program might be designed with a high-level of structure in the first level of the course (Identifying), moving to greater student autonomy (Authoring) in the higher level courses. The matrix can, therefore, be used to help map characteristics of flipped learning at different stages of the program by providing a tool to demonstrate development and help ensure a shared understanding across the program.

Taking this holistic view of flipped learning implementation demonstrates that a broad conceptualisation of flipping is actually its greatest strength. The notion of balancing, scaffolding and leveraging a student's learning through multiple dimensions, as shown through the quadrants, improves the offering, but also empowers educators to design their own flipped instance that is fit for purpose.

\section{CONCLUSIONS}

With the public boom of flipped learning, the requirement of proposing a practical design framework becomes more pressing. O'Flaherty and Phillips (2015), in their scoping review, identified that this is leading to a situation where there is "added pressure for many educators to renew their curriculum with an approach that they may not fully understand” (p. 94). They went on to recommend that a capacity to blueprint conceptual frameworks into context-specific-plans be developed for the effective implementation of flipped learning.

In this study, we have developed a 'Flipped Learning Matrix model' based on two dimensions: content-focused to process-focused and teacher-led to student-led. Informed by Goodyear's (2005) pedagogical framework, we argue that the model can be used to situate existing practice and help inform the design of flipped learning approaches. We believe that the essence of flipped learning is a strategy that forms part of the overarching pedagogical philosophies that educate more active, engaged and autonomous learners, rather than merely structural inverting of the process of learning or as a technology implementation.

\section{ACKNOWLEDGMENTS}

This paper was produced as part of the ISSoTL International Collaborative Writing Group 2015 initiative. The authors would like to thank our fellow writing group members for their feedback along the way, Kelly Matthews and Mick Healey for efforts in organising and facilitating the groups. We would also like to express our appreciation to the reviewers for their valuable feedback.

Martin Jenkins is Head of Academic Development at Coventry University, UK.

Rena Bokosmaty is a PhD student, School of Chemistry at University of Sydney, Australia.

Melanie Brown is Senior Academic Developer at RMIT University, Vietnam.

Chris Browne is Lecturer, Research School of Engineering at Australian National University, Australia.

Qi Gao is Lecturer, School of Automation at Beijing Institute of Technology, China.

Julie Hanson is Lecturer of Nursing at University of the Sunshine Coast, Australia.

Ketevan Kupatadze is Senior Lecturer of Spanish, Department of World Languages and Cultures at Elon University, US. 


\section{REFERENCES}

Abeysekera, L., \& Dawson, P. (2015). Motivation and cognitive load in the flipped classroom: Definition, rationale and a call for research. Higher Education Research \& Development, 34(1), 1-14.

Berens, K. I. (2014, January 23). Double flip: 3 insights flipping the humanities seminar. Hybrid Pedagogy.

Bergmann, J., \& Sams, A. (2012). Flip your classroom: Reach every student in every class every day. Eugene, Or: International Society for Technology in Education.

Biggs, J. B., \& Collis, K. (1982), Evaluating the quality of learning: The SOLO taxonomy. New York: Academic Press.

Bloom, B. S., Engelhart, M. D., Furst, E. J., Hill, W. H., \& Krathwohl, D. R. (1956). Taxonomy of educational objectives: The classification of educational goals. Handbook I: Cognitive domain. New York: David McKay Company.

Dewey, J. (1916). Democracy and education: An introduction to the philosophy of education. New York: Macmillan.

Educause Learning Initiative. (2012). 7 Things You Should Know About Flipped Classrooms. EDUCAUSE Learning Initiative (ELI).

Flipped Learning Network. (2015, November 23).

Flynn A. B. (2012), Development of an online, post-class question method and its integration with teaching strategies, Journal of Chemical Education, 89, 456-464.

Flynn, A. B. (2015). Structure and evaluation of flipped chemistry courses: Organic \& spectroscopy, large and small, first to third year, English and French. Chemistry Education Research and Practice (1109-4028), 16 (2), p. 198-211.

Garrison, D. R., Anderson A. T., \& Archer W. (2010). The first decade of the community of inquiry framework: A retrospective. Internet and Higher Education, 13, 5-9.

Gerstein, J. (2012). The flipped classroom: The full picture. Amazon Digital Services, Incorporated.

Goodyear, P. (2005). Educational design and networked learning: Patterns, pattern languages and design practice. Australasian Journal of Educational Technology, 21(1), p.82-101.

Graham, C. R., Henri, C. R., \& Gibbons, A. S. (2014). Developing models and theory for blended learning research. In A. G. Picciano, C. D. Dziuban, \& C. R. Graham (Eds.), Blended learning: Research perspectives, volume 12 (pp. 13-38). New York. NY: Routledge.

Healey, M. (2005) Linking research and teaching: Exploring disciplinary spaces and the role of inquiry-based learning. In R. Barnett (Ed.), Reshaping the university: New relationships between research, scholarship and teaching, (pp. 67-78). Maidenhead: SRHE/Open University Press.

Kim, M. K., Kim, S. M., Khera, O., \& Getman, J. (2014). The experience of three flipped classrooms in an urban university: An exploration of design principles. The Internet and Higher Education, 22, 37-50.

Kolb, D. A. (1984). Experiential learning: Experience as the source of learning and development. New Jersey: FT Press.

Lage, M. J., Platt, G. J., \& Treglia, M. (2000). Inverting the classroom: A gateway to creating an inclusive learning environment. Journal of Economic Education, (Winter 2000), 30-43.

Levy, P. (2015). Technology-supported design for inquiry-based learning. In M. Li \& Y. Shao (Eds.), Exploring learning and teaching in higher education (pp. 289-304). Berlin: Springer.

Levy, P., Little, S., McKinney, P., Nibbs, A., \& Wood, J. (2009). The Sheffield companion to inquiry-based learning. Sheffield, UK: CILASS.

Lipman, M. (2003). Thinking in education (2nd ed.). Cambridge, UK: Cambridge University Press.

Mason, G., Shuman, T., \& Cook, K. (2013). Comparing the effectiveness of an inverted classroom to a traditional classroom in an upper-division engineering course. IEEE Transactions on Education, 56(4), 430-435.

Mazur, E. (1997). Peer instruction: A user's manual. Upper Saddle River, New Jersey: Prentice Hall.

O'Flaherty, J., \& Phillips, C. (2015). The use of flipped classrooms in higher education: A scoping review. The Internet and Higher Education, 25, 85-95.

Redekopp, M. W., \& Ragusa, G. (2013). Evaluating flipped classroom strategies and tools for computer engineering. In Proceedings of the 120th American Society of Engineering Education Annual Conference \& Exposition. Atlanta, GA.

Shea, P. \& Bidjerano, T. (2010). Learning presence: Towards a theory of self-efficacy, self-regulation, and the development of a communities of inquiry in online and blended learning environments. Computers \& Education, 55(4), 1721-1731.

76 Jenkins, M., Bokosmaty, R., Brown, M., Browne, C., Gao, Q., Hanson, J., \& Kupatadze, K. (2017). Enhancing the design and analysis of flipped learning strategies. Teaching \& Learning Inquiry, 5(1).

http://dx.doi.org/10.20343/teachlearninqu.5.1.6 
Shea, P., Hayes, S., Smith, S. U., Vickers, J., Bidjerano T, Pickett. A., \& Shoubang, J. (2012). Learning presence: Additional research on a new conceptual element within the Community of Inquiry (Col) framework. Internet and Higher Education, 15(2), 89-95.

Staker, H., \& Horn, M. B. (2012). Classifying k-12 blended learning. Mountain View, CA: Innosight Institute. Westermann, E. B. (2014). A half-flipped classroom or an alternative approach? Primary sources and blended learning. Educational Research Quarterly, 38(2), 43-57.

Wood, J., Bell, E., Hill, K., Huntington, J., \& Scorpo, A. L. (2014). Making digital history: Students as partners in online learning, teaching and research. Making Digital History, University of Lincoln.

Zappe, S., Leicht, R., Messner, J., Litzinger, T., \& Lee, H. (2009). "Flipping” the classroom to explore active learning in a large undergraduate course. In Proceedings of the 2009 American Society for Engineering Education Annual Conference and Exhibition. Austin, TX.

Copyright for the content of articles published in Teaching \& Learning Inquiry resides with the authors, and copyright for the publication layout resides with the journal. These copyright holders have agreed that this article should be available on open access under a Creative Commons Attribution License 4.0 International (https://creativecommons.org/licenses/by/4.0). The only constraint on reproduction and distribution, and the only role for copyright in this domain, should be to give authors control over the integrity of their work and the right to be properly acknowledged and cited, and to cite Teaching \& Learning Inquiry as the original place of publication. Readers are free to share these materials - as long as appropriate credit is given, a link to the license is provided, and any changes are indicated. 